\title{
Erratum to: Pain and health-related quality of life in patients with advanced solid tumours and bone metastases: integrated results from three randomized, double-blind studies of denosumab and zoledronic acid
}

\author{
Roger von Moos • Jean-Jacques Body • Blair Egerdie • Alison Stopeck • Janet E. Brown • \\ Danail Damyanov • Lesley J. Fallowfield • Gavin Marx • Charles S. Cleeland • \\ Donald L. Patrick • Felipe G. Palazzo • Yi Qian • Ada Braun • Karen Chung
}

Published online: 10 June 2014

(C) Springer-Verlag Berlin Heidelberg 2014

Erratum to: Support Care Cancer (2013) 21:3497-3507

DOI 10.1007/s00520-013-1932-2

The figures in the original version of this article unfortunately contained the following errors.

- In Fig. $2 b$, the values presented in the bars were proportions of all patients, not proportions of patients with no/ mild pain at baseline. All other information in the figure was correct. The corrected figure appears below:

The online version of the original article can be found at http://dx.doi.org/ 10.1007/s00520-013-1932-2.

R. von Moos $(\bowtie)$

Kantonsspital Graubünden, Loëstrasse 170, 7000 Chur, Switzerland

e-mail: Roger.vonmoos@ksgr.ch

J.-J. Body

Chu Brugmann, Université Libre De Bruxelles, Brussels, Belgium

B. Egerdie

Urology Associates/Urologic Medical Research,

Kitchener, ON, Canada

\section{A. Stopeck}

Arizona Cancer Center, University of Arizona, Tucson, AZ, USA

\section{J. E. Brown}

Cancer Research UK Experimental Cancer Medicine Centres,

Leeds and Sheffield, UK

D. Damyanov

National Hospital for Treatment in Oncology, Sofia, Bulgaria
L. J. Fallowfield

Sussex Health Outcomes Research \& Education in Cancer (SHORE-C), University of Sussex, Brighton, UK

G. Marx

Sydney Adventist Hospital, University of Sydney, Sydney, NSW, Australia

C. S. Cleeland

University of Texas MD Anderson Cancer Center, Houston, TX, USA

D. L. Patrick

University of Washington, Seattle, WA, USA

F. G. Palazzo

CAIPO, San Miguel de Tucuman, Tucuman, Argentina

Y. Qian · A. Braun · K. Chung

Amgen Inc., Thousand Oaks, CA, USA 




- In Fig. 4b, the correct label for proportion of subjects in the zoledronic acid group was $65.0 \%$ (not $65.3 \%$ ) at Month 9. All other information in the figure was correct.

- In Fig. 4c, the number of subjects was $n=2,186$ for denosumab $120 \mathrm{mg}$ Q4W and $n=2,155$ for zoledro- nic acid $4 \mathrm{mg}$ Q4W. The correct labels for the proportion of subjects in the zoledronic acid group were $6.1 \%$ (not $6.0 \%$ ) at Month 2 and $9.1 \%$ (not $9.0 \%$ ) at Month 4. All other information in the figure was correct. 